\title{
The European technical report on aquatic effect-based monitoring tools under the water framework directive
}

Ann-Sofie Wernersson ${ }^{1}$, Mario Carere ${ }^{2 *}$, Chiara Maggi ${ }^{3}$, Petr Tusil ${ }^{4}$, Premysl Soldan ${ }^{4}$, Alice James ${ }^{5}$, Wilfried Sanchez ${ }^{5}$, Valeria Dulio ${ }^{5}$, Katja Broeg ${ }^{6}$, Georg Reifferscheid ${ }^{7}$, Sebastian Buchinger ${ }^{7}$, Hannie Maas ${ }^{8}$, Esther Van Der Grinten ${ }^{9}$, Simon O'Toole ${ }^{10}$, Antonella Ausili ${ }^{3}$, Loredana Manfra ${ }^{3}$, Laura Marziali ${ }^{11}$, Stefano Polesello ${ }^{11}$, Ines Lacchetti ${ }^{2}$, Laura Mancini², Karl Lilja ${ }^{12}$, Maria Linderoth ${ }^{12}$, Tove Lundeberg ${ }^{12}$, Bengt Fjällborg' ${ }^{1}$, Tobias Porsbring ${ }^{1}$, DG Joakim Larsson ${ }^{13}$, Johan Bengtsson-Palme ${ }^{13}$, Lars Förlin ${ }^{13}$, Cornelia Kienle $^{14}$, Petra Kunz ${ }^{14}$, Etienne Vermeirssen ${ }^{14}$, Inge Werner ${ }^{14}$, Craig D Robinson ${ }^{15}$, Brett Lyons ${ }^{16}$, loanna Katsiadaki ${ }^{16}$, Caroline Whalley ${ }^{17}$, Klaas den Haan ${ }^{18}$, Marlies Messiaen ${ }^{19}$, Helen Clayton ${ }^{20}$, Teresa Lettieri ${ }^{21}$, Raquel Negrão Carvalho ${ }^{21}$, Bernd Manfred Gawlik ${ }^{21}$, Henner Hollert ${ }^{22}$, Carolina Di Paolo ${ }^{22}$, Werner Brack ${ }^{23}$, Ulrike Kammann ${ }^{24}$ and Robert Kase ${ }^{14}$

\begin{abstract}
The Water Framework Directive (WFD), 2000/60/EC, requires an integrated approach to the monitoring and assessment of the quality of surface water bodies. The chemical status assessment is based on compliance with legally binding Environmental Quality Standards (EQSs) for selected chemical pollutants (priority substances) of EU-wide concern. In the context of the mandate for the period 2010 to 2012 of the subgroup Chemical Monitoring and Emerging Pollutants (CMEP) under the Common Implementation Strategy (CIS) for the WFD, a specific task was established for the elaboration of a technical report on aquatic effect-based monitoring tools. The activity was chaired by Sweden and co-chaired by Italy and progressively involved several Member States and stakeholders in an EU-wide drafting group. The main aim of this technical report was to identify potential effect-based tools (e.g. biomarkers and bioassays) that could be used in the context of the different monitoring programmes (surveillance, operational and investigative) linking chemical and ecological status assessment. The present paper summarizes the major technical contents and findings of the report.
\end{abstract}

Keywords: Effect-based tools; Priority substances; Aquatic ecosystems; Water Framework Directive; Bioassays; Chemical pollution; Biomarkers

\section{Review}

\section{Introduction}

The Water Framework Directive (WFD), 2000/60/EC, [1] requires an integrated approach to the monitoring and assessment of the quality of surface water bodies in the European Union. The assessment of ecological status takes into account the effects at the population and community levels, based on the use of specific indices and ecological

\footnotetext{
* Correspondence: mario.carere@iss.it

${ }^{2}$ Department of Environment and Primary Prevention, ISS-Italian Institute of Health, Viale Regina Elena, 299, 00161 Rome, Italy

Full list of author information is available at the end of the article
}

quality ratios. The chemical status assessment is based on compliance with legally binding Environmental Quality Standards (EQSs) for 53 selected chemical pollutants (priority substances) of EU-wide concern [2].

Chemical analysis generally requires a priori knowledge about the type of substances to be monitored as, for technical and economic reasons, it is not possible to analyse, detect and quantify all substances that are present in the aquatic environment. Even for the thousands of unique substances registered under Registration, Evaluation, Authorisation and Restriction of Chemicals (REACH) it would be highly challenging to perform a chemical

\section{实}


monitoring programme on the aquatic environment. Furthermore, to estimate the risk of effects related to the large number of substances that are present and detected in the environment (including pollutants of emerging concern, metabolites and transformation products), it would be necessary to develop a very large number of assessment criteria (EQS). Such assessment criteria for chemicals are generally developed substance by substance, based on laboratory studies, and usually do not consider the consequences of simultaneous exposure to multiple chemicals [3] occurring in the environment, possibly giving rise to cumulative effects [4].

In the mandate for 2010 to 2012 of the European subgroup Chemical Monitoring and Emerging Pollutants (CMEP) under the WG "Chemical Aspects" of the Common Implementation Strategy (CIS) for the WFD, a specific task was foreseen for the elaboration of a technical report on effect-based tools [5]. The activity was chaired by Sweden and co-chaired by Italy and progressively involved several Member States and stakeholders in an EU-wide drafting group (47 experts). According to the mandate from the CMEP, the aim of the report was to identify potential effect-based tools (e.g. bioassays, biomarkers and ecological indicators) that could be used in the context of the different monitoring programmes (surveillance, operational and investigative) linking the chemical and ecological status assessment.

\section{Technical report}

The technical report on aquatic effect-based monitoring tools (Additional file 1) [6] aims at presenting the state of the art of aquatic effect-based monitoring tools and describing how these tools can help EU Member States to make monitoring programmes more efficient (including reduction of monitoring costs). The report further contains specific sections on the use of such tools in marine systems such as the Regional Seas Conventions and the Marine Strategy Framework Directive (MSFD) 2008/56/EC. The MSFD has foreseen the use of effect-based tools: in particular, the indicators related to Descriptor 8 (contaminants and pollution effects) of the MSFD should include effects from hazardous substances on ecosystem components.

For reasons of clearness, the tools described in the report are categorised into three main groups, primarily depending on the type of monitoring approach used:

1) Bioassays, both in vitro and in vivo, which measure the toxicity of environmental samples under defined laboratory conditions, on cellular or individual levels, respectively.

2) Biomarkers, i.e. biological responses at the cellular or individual levels, measured in field-exposed organisms.
3) Ecological methods, measuring changes observed at higher biological organisation levels, i.e. the population and/or community.

In Europe, several of the tools described in the report are already used for both marine and limnic applications $[7,8]$. Biomarkers are included in the monitoring programmes of Regional Seas Conventions to detect the presence of substances or combinations of substances not previously identified as a concern and to identify regions of decreased environmental quality. Bioassays are used for example to support risk assessment and management of contaminated sediments and provide decision support for reducing the release of toxic substances into the environment (e.g. in the evaluation of dredged sediments that are considered for sea disposal and whole effluent assessments in the permitting process). They are also used in broad screening of different pollutant sources (such as sewage treatment plant effluents). Other applications include, for example, alarm systems directly triggering control measures (e.g. closing drinking water intakes). Effect-based tools support also the ecotoxicological characterisation and classification of hazardous wastes in the context of the Waste Framework Directive (2008/98/EC). Specific sections of the report are dedicated to EDA/TIE approaches and OMICS.

The report was approved by the CMEP subgroup in Gent, Belgium, (October 2012), by the Working Group on Chemical Aspects in Brussel, Belgium (April 2013), by the Strategic Coordination Group (SCG) of the WFD in Brussel (October 2013) and endorsed by the Water Director Meeting in Vilnius, Lithuania (December 2013).

\section{Effect-based tools in the WFD}

The WFD mandates three monitoring programmes:

Surveillance monitoring aimed to supplement and validate an impact analysis, support efficient and effective design of future monitoring programmes and assess longterm changes in natural conditions and changes resulting from anthropogenic activity. Monitoring is performed at least once every management cycle (usually every 6 years).

Operational monitoring aimed to establish the status of water bodies identified as being at risk of failing to meet the WFD environmental objectives and assess any changes in the status resulting from the programme of measures.

Investigative monitoring aimed to determine reasons for exceedances or predicted failure to achieve environmental objectives if the reasons are not already known and to determine the magnitude and impacts of accidental pollution.

As with all other components of a monitoring programme, it is important to assess the suitability of different effect-based tools against the specified objectives of the monitoring programmes [9]. The suitability 
of any particular approach must be evaluated in terms of method, cost, practicality and capability to provide information that can be translated into management practices useful for achieving the monitoring programme objectives.

As it has been already evident from previous CIS guidance documents, it is possible to identify several objectives for the use of effect-based tools in a WFD context, some of them are mentioned below:

- As screening tools, in the framework of the pressures and impacts assessment to aid in the prioritisation of water bodies.

- To establish early warning systems.

- To prioritise further studies in areas that are not identified as being at risk because they are located far from known local sources.

- To take the effects of chemical mixtures or chemicals that are not analysed into account (e.g. to support investigative monitoring where causes of a decline of specific species are unknown).

- To provide additional support in water and sediment quality assessment, though not as a replacement for conventional chemical and ecological monitoring under the WFD.

Effect-based tools are particularly suitable as part of investigative monitoring programmes, for which the regulatory requirements are determined less formally. However, as with any investigative monitoring, the optimum set of tools varies on a case-by-case basis. The optimal approach will frequently involve several effectbased tools as well as chemical analysis, as illustrated by several of the case studies described in the Appendix section of the report. To optimize cost-effectiveness, it is often wise to make use of the same samples for both chemical and effect-based analyses.

\section{Bioassays in vitro}

The use of in vitro assays is increasing for ethical reasons in order to comply with the regulations on animal experimentation. They measure effects at the subcellular level, such as receptor activation and DNA damage, rather than investigate cells or tissues of organisms [10] exposed in the field (as it is the case with biomarkers), the effects are studied in cells after exposure to environmental samples [11]. An advantage of this approach is that in vitro bioassays can often be performed on many different matrixes (such as concentrated extracts of surface water, sediment or pore water samples, biological tissues, passive samplers and effluents). Additional advantages are that only small amounts of sample are generally needed and exposure time is short compared to the time needed for an in vivo assay to detect a response.
In most cases, in vitro assays are considered highly sensitive, because they measure effects at a low organisational level. Many in vitro assays are suitable for screening and high-throughput/automated applications and can be added to the analytical tool package at comparatively lower costs (especially if taking into account the number of substances they respond to).

Table 1 presents some in vitro assays that were nominated for monitoring purposes in a Swedish workshop [12]. The table also includes information about the mode of action the assay responds to.

The use of in vitro assays is also common outside Europe; for example, they are largely used in the context of the U.S. A. Programme US TOX 21. For some in vitro bioassays, results are expressed in chemical equivalents, comparing the response induced by the sample to that induced by the reference chemical (positive control). However, before comparing such bioassay results to water quality criteria developed for single chemicals or a number of specific chemicals, it is necessary to consider that the assay can respond to different combined substances that have the same mode of action, e.g. via receptor activation. Generally, for a mixture of agonistic substances with the same mode of action, the biological signal is higher than for a single substance which makes in vitro assays highly suitable as screening tools for environmental samples. They integrate

\section{Table 1 In vitro assays and their modes of action}

\begin{tabular}{|c|c|}
\hline Name/s of assay & Mode of action/endpoint \\
\hline AR CALUX (anti-) & Androgen receptor (activation or blocking) \\
\hline DR CALUX & $\mathrm{AH}$ receptor binding \\
\hline ER CALUX (anti-) & Alpha and beta/estrogen receptors \\
\hline GR CALUX (anti-) & Glucocorticoid receptor \\
\hline PAH CALUX & AH receptor binding \\
\hline PR CALUX & Progesterone receptor \\
\hline $\begin{array}{l}\text { Acetylcholinesterase } \\
\text { inhibition assay }\end{array}$ & $\begin{array}{l}\text { Inhibition of acetylcholinesterase } \\
\text { activity }\end{array}$ \\
\hline $\begin{array}{l}\text { Carboxylesterase } \\
\text { inhibition assay }\end{array}$ & Inhibition of carboxylesterase activity \\
\hline Ames & Mutagenicity \\
\hline umuC & Primary DNA damage \\
\hline TTR-binding & $\begin{array}{l}\text { Competition with thyroid hormone } \\
\text { for binding to TTR (transport protein) }\end{array}$ \\
\hline TRb CALUX & Thyroid receptor beta \\
\hline EROD & EROD induction \\
\hline YES & ER receptor \\
\hline YAS & AR receptor \\
\hline P-53 accumulation & Genotoxicity \\
\hline Green screen & Genotoxicity \\
\hline RYA & ER receptor \\
\hline ABC assay & Antibiotic activity \\
\hline
\end{tabular}


effects of all substances with the same mode of action, e.g. estrogen receptor binding. As such integrative detection tools, in vitro assays are also able to quantify and distinguish agonistic and antagonistic effects.

Although many in vitro bioassays can be used on any matrix/extract, some are more suited for the assessment of certain matrices than others, in part because they have been so far only validated for certain uses but also because relevant substances eliciting certain types of responses are primarily found in certain compartments. When using in vitro bioassays, we must be aware that we use highly specific systems to detect chemicals interacting with a specific cellular receptor. These cellular events have been shown to be an important link in the development of specific adverse effects on higher levels of biological organisation. However, it is obvious that simplified in vitro systems do not cover the complexity. Some drawbacks with in vitro tools are that, as opposed to in vivo bioassays and biomarkers, the systems studied are highly simplified when compared to the complexity of whole organisms. Thus, the potential interactions between different receptors, cells and organs are not detected.

In vitro assays are suitable and sometimes necessary when it is needed to conduct follow-up studies using biomarkers. In comparison to most biomarkers, they can easily be used to track local pollution sources by sampling water and sediment in a pollution gradient or effluents from suspected point sources. In vitro assays are also valuable in effect-directed analysis (EDA)/toxicity identification evaluation (TIE) approaches to identify toxic fractions and provide guidance for the identification of causative agents.

\section{Bioassays in vivo}

In vivo bioassays are tests where whole living organisms (including bacteria) are exposed to environmental samples, such as surface water, sediment, wastewater, dredge material or extracts from such samples. Tests are performed in the laboratory or, less frequently, in the field ("in situ" bioassays) [13].

The "endpoint" is the type of effect that is measured in a toxicity test, and some examples that are frequently used in this context are mortality, immobilization, fertilisation rate, hatching rate, embryo development, effects on growth of individuals (e.g. weight), effects on growth of populations (e.g. number of individuals), metabolic or physiological changes, reduced swimming activity, bioluminescence and specific molecular/biochemical responses.

Table 2 reports the most common in vivo bioassays applied by certain Member States within aquatic monitoring programmes.

In general, in vivo bioassays are broad spectrum assays, i.e. an in vivo bioassay responds to a variety of substances and different types of toxicity. An example is the "fish embryo acute toxicity (FET) test," recently adopted by the OECD N.236 of 26 July 2013, that is based on individual exposure of eggs to evaluate the embryotoxicity of samples with the aim to detect contaminants (relevant for the WFD) such as industrial chemicals, pesticides, pharmaceuticals and biocides.

Nevertheless, it is important to underline that the evaluation of toxic effects is based on the responses observed in several species, because they can exhibit intrinsic differences in terms of sensitivity to various chemicals; it also depends on the endpoints measured in the test [14]. Both short- and long-term in vivo bioassays should preferably be carried out using at least three species from different taxonomic groups and trophic levels (primary producer, decomposer/saprophytic, detritivore/filter feeder and consumer). A battery of ecotoxicological tests should have sufficient sensitivity and discriminatory power and respond to as many contaminant groups as possible.

\section{Biomarkers}

Biomarkers are molecular, biochemical, cellular and physiological indicators of contaminant stress measured in organisms resident or exposed in situ in a specific location. They are used in the monitoring programmes of Regional Seas Conventions and more recently in the MSFD to identify the impact from substances or combinations of substances not previously identified to be of concern, study trends and identify regions of decreased environmental quality [15]. Contrary to bioassays but similar to the ecological/community-based tools, biomarkers are analysed on field-exposed, usually resident, organisms. The sampling step is therefore primarily focused on the organisms that should to be examined. However, active monitoring based on caged organisms can also be used to measure biomarkers.

It is important to detect deleterious effects due to chemicals before significant effects at the population level occur. Damage at the population and ecosystem level can take a long time to repair. For certain trophic levels, recolonisation may take much longer than the 6-year management cycles considered in the WFD and MSFD. Ecological tools or indices are not predictive of damage, whereas several biomarkers can be used as early warning systems because they can detect effects caused by chemical substances and other environmental stress at an early stage.

Biomarkers are frequently divided into two different categories, depending on the number of substances/ groups of substances they are known to respond to:

- General (integrative) biomarkers that respond to several classes of toxic substances and, frequently, also to other types of stressors.

- Specific biomarkers that respond primarily to only a few/groups of/substances. 
Table 2 Examples of in vivo bioassays applied by certain member states within aquatic monitoring programmes

\begin{tabular}{|c|c|c|c|c|}
\hline Organism & Test item & Endpoint & Species & Exposure \\
\hline \multirow[t]{2}{*}{ Bacteria } & $w, w s, e, p$ & Bioluminescence & Aliivibrio fischeri (f/m) & 5 to $30 \mathrm{~min}$. \\
\hline & & Enzyme activity & Arthrobacter globiformis ( $f$ ) & $2 \mathrm{~h}$ \\
\hline \multirow[t]{5}{*}{ Algae } & $w, e, p$ & Growth & Phaeodactylum tricornutum (m) & $72 \mathrm{~h}$ \\
\hline & & & Skeletonema costatum (m) & \\
\hline & & Growth & Desmodesmus subspicatus ( $f$ ) & $72 \mathrm{~h}$ \\
\hline & & & Pseudokirchneriella subcapitata $(\mathrm{f})$ & \\
\hline & & Growth & Ceramium tenuicorne (m) & 7 days \\
\hline \multirow[t]{2}{*}{ Plants } & $w, e, p$ & Growth & Lemna minor $(f)$ & 7 days \\
\hline & ws & Growth & Myriophyllum aquaticum (f) & 10 days \\
\hline Rotifera & $w, e, p$ & Mortality & Brachionus plicatilis & 24 to $48 \mathrm{~h}$ \\
\hline \multirow[t]{6}{*}{ Crustacea (amphipods) } & ws & Mortality & Corophium spp. (and other amphipods) (m) & 10 days \\
\hline & $w, e, p$ & Mortality & Artemia franciscana $(\mathrm{m})$ & 24 h, 14 days \\
\hline & & Mortality & Acartia tonsa $(\mathrm{m})$ & $96 \mathrm{~h}$ \\
\hline & & & Tigriopus fulvus (m) & \\
\hline & & Mobility, mortality, reproduction & Daphnia magna (f) & 24/48 h, 21 days \\
\hline & & & Cerodaphnia dubia (f) & \\
\hline Nematoda & ws & Mortality, fertility, reproduction & Caenorhabditis elegans ( $f$ ) & $96 \mathrm{~h}$ \\
\hline Annelida & ws & Mortality, reproduction & Lumbriculus variegatus ( $f$ ) & 28 days \\
\hline Insecta & W, ws & Mortality, reproduction & Chironomus riparius ( $\mathrm{f}$ ) & 48 h, 28 days \\
\hline \multirow[t]{3}{*}{ Bivalvia } & $w, e, p$ & Development & Crassostrea gigas (m) & 24 to $72 \mathrm{~h}$ \\
\hline & & & Mytilus galloprovincialis (m) & \\
\hline & & & Tapes philippinarum (m) & \\
\hline \multirow[t]{2}{*}{ Echinodermata } & $w, e, p$ & Fertilisation & Paracentrotus lividus (m) & $\leq 72 \mathrm{~h}$ \\
\hline & & Development & Sphaerechinus granularis (m) & \\
\hline Polychaeta & ws & Mortality & Hediste diversicolor (m) & 10 days \\
\hline \multirow[t]{2}{*}{ Vertebrata (fishes) } & $w, e, p$ & Mortality and genotoxic damage & Danio rerio (and embryos of other species) ( $f$ ) & 96 h, 28 days \\
\hline & & & Dicentrarchus labrax (m) & \\
\hline
\end{tabular}

w, water; e, elutriate; $p$, pore water; ws, whole sediment; f, freshwater; $m$, brackish and marine.

For example, imposex is considered to be a highly specific effect, responding primarily to organic tin compounds such as tributyltin (TBT), whereas lysosomal stability is a more general biomarker for cellular stress. Both general and specific biomarkers can be useful, depending on the monitoring goals and the level of prior knowledge regarding the type of contaminants present at the given location. Because general biomarkers respond to several classes of compounds, they cover more substances and are therefore valuable in identifying areas of concern in environments exposed to complex mixtures of stressors. Specific biomarkers are, for example, valuable in second tier assessments to detect and identify the effects of specific types of substances in impacted locations.

Table 3 presents biomarkers used in the integrated monitoring approach proposed by International Council for the Exploration of the Sea (ICES) and the Regional Seas Conventions.

Biomarkers of exposure allow statements about the quality and/or quantity of exposure, whereas with biomarkers of effect statements about effects and the health status of exposed organisms can be made.

Exposure biomarkers, such as ethoxyresorufin-Odeethylase (EROD), can provide a sensitive indication of cellular changes at the enzyme level, which often represent the first warning signals of environmental disturbance. EROD can be used to detect exposure to classes of organic pollutants such as co-planar polychlorinated biphenyls (PCB), polycyclic aromatic hydrocarbons (PAH), planar dibenzodioxins (PCDD) and dibenzofurans (PCDF). Metallothioneins, peroxisomal enzymes (e.g. acyl CoA oxidase) and inhibition of acetylcholinesterase activity are other more or less 
Table 3 Biomarkers used in the integrated monitoring approach proposed by ICES and the Regional Seas Conventions

\begin{tabular}{|c|c|c|}
\hline Biomarker & Description & Responds to \\
\hline EROD activity & $\begin{array}{l}\text { Biotransformation enzyme induced by } \\
\text { planar hydrocarbon }\end{array}$ & PCBs, PAHs and dioxin-like compounds \\
\hline $\begin{array}{l}\text { Acetylcholinesterase (AChE) } \\
\text { activity }\end{array}$ & Enzyme implicated in nervous transmission & $\begin{array}{l}\text { Organophosphates, carbamates and similar } \\
\text { molecules }\end{array}$ \\
\hline Vitellogenin (VTG) in male fish & $\begin{array}{l}\text { A precursor of egg yolk, normally synthesized } \\
\text { by female fish }\end{array}$ & estrogenic endocrine disrupting compounds \\
\hline Metallothionein (MT) & $\begin{array}{l}\text { Metal scavenger implicated in protection } \\
\text { against oxidative stress }\end{array}$ & Heavy metals and inducer of oxidative stress \\
\hline $\begin{array}{l}\text { Amino-levulinic acid } \\
\text { deshydratase (ALAD) }\end{array}$ & Enzyme implicated in amino-acid metabolism & Lead exposure \\
\hline Lysosomal stability & $\begin{array}{l}\text { General health, lysosomes play a key } \\
\text { role in liver injury caused by various } \\
\text { xenobiotics }\end{array}$ & $\begin{array}{l}\text { Several classes of pollutants, including PAH, inducer } \\
\text { of oxidative stress, metals and organochlorines }\end{array}$ \\
\hline DNA adducts & $\begin{array}{l}\text { Alteration of DNA structure able to } \\
\text { disturb DNA function }\end{array}$ & $\begin{array}{l}\text { Genotoxic compounds including PAHs and other } \\
\text { synthetic organic compounds }\end{array}$ \\
\hline $\begin{array}{l}\text { Imposex biomarkers (e.g. VDSI) } \\
\text { in molluscs }\end{array}$ & $\begin{array}{l}\text { Imposition of male sex characteristics } \\
\text { on female molluscs }\end{array}$ & TBT \\
\hline PAH bile metabolites & $\begin{array}{l}\text { PAH metabolites in bile/urine represent the } \\
\text { final stage of the biotransformation process }\end{array}$ & Indirect indicator of PAH exposure \\
\hline Liver histopathology & $\begin{array}{l}\text { General indication about liver damage but can } \\
\text { be diagnostic depending on the type of lesion }\end{array}$ & $\mathrm{PAHS}$ \\
\hline Macroscopic liver neoplasms & Visible fish liver tumours & Cancer inducing substances; PAHs \\
\hline Externally visible fish diseases & $\begin{array}{l}\text { Overall organism health External investigations } \\
\text { of fish, significant changes indicate chronic stress }\end{array}$ & Several classes of pollutants and pathogens \\
\hline Intersex in fish & $\begin{array}{l}\text { Presence of ovarian tissue in male fish gonads compromising } \\
\text { reproductive capacity }\end{array}$ & estrogenic endocrine disrupting compounds \\
\hline Micronucleus & $\begin{array}{l}\text { Damage to genetic material of organisms; could } \\
\text { affect their health and potentially also their } \\
\text { offspring. }\end{array}$ & $\begin{array}{l}\text { Substances causing chromosomal aberrations } \\
\text { (clastogens) }\end{array}$ \\
\hline $\begin{array}{l}\text { Amphipod/fish embryo } \\
\text { alterations }\end{array}$ & Embryo malformations (viviparous organisms) & $\begin{array}{l}\text { Overall organism health; strong correlation observed } \\
\text { between malformed embryos and concentrations } \\
\text { of metals and organic compounds }\end{array}$ \\
\hline Stress proteins & Early stage effects, including oxidative stress & Responds to many types of stress factors \\
\hline Benthic diatom malformations & Malformations; overall organism health & $\begin{array}{l}\text { Significant response to metals and several pesticides, } \\
\text { but less to other priority substances }\end{array}$ \\
\hline Comet assay & Sensitive tool to detect genetic damage & Substances causing DNA strand breaks \\
\hline $\begin{array}{l}\text { Mussel histopathology } \\
\text { (gametogenesis) }\end{array}$ & $\begin{array}{l}\text { Histological studies of, e.g. digestive } \\
\text { gland and tube }\end{array}$ & $\begin{array}{l}\text { Many groups of substances, including PAHs, PCBs } \\
\text { and heavy metals }\end{array}$ \\
\hline Stress on stress & Survival in air & $\begin{array}{l}\text { Many groups of substances, including crude oil, } \\
\text { copper ions and PCBs }\end{array}$ \\
\hline Scope for Growth & $\begin{array}{l}\text { Measures alterations in the energy available } \\
\text { for growth and reproduction. }\end{array}$ & $\begin{array}{l}\text { Many groups of substances, including } \\
\text { di(2-ethylhexyl)phthalate (DEHP), aromatics, } \\
\text { pentachlorophenol (PCP), copper, TBT and dichlorvos }\end{array}$ \\
\hline
\end{tabular}

specific exposure responses towards trace metals, organic chemicals and organophosphate pesticides, respectively.

On the other hand, biomarkers of effect indicate the occurrence of various forms of molecular to cellular/tissue alterations, although the health-related effects may differ in terms of toxicological and ecological relevance. Some effect biomarkers detect effects at early stages (such as genetic changes), whereas others, such as imposex, are related to later stages from a population risk perspective.

\section{Ecological methods}

The assessment criteria (primarily based on values of biodiversity indices) selected as the biological quality elements of the WFD do not respond in a specific way to the effects of hazardous substances. Specific tools for the assessment of hazardous substances applied in the context of WFD monitoring are extremely rare. Therefore, ecological status related to hazardous substances is generally based on individual pollutant concentrations, which may or 
may not be consistent with the ecological quality status assessment.

A new approach within biomonitoring is to consider the ecological role of communities, based on their functional, rather than structural composition, through the identification of species traits [16]. The resistance and resilience characters of individual taxa determine the response of communities to disturbance. Undisturbed communities display a diversity of species traits, whereas the communities downstream of a pollution source consist of those species that have a suite of traits which convey tolerance to the new conditions. Species that do not have these traits cannot survive [17]. The advantage of using functional traits instead of taxonomic composition (an entirely structural approach) of communities is bound to the a priori predictable response of traits to individual stressors, because each selection pressure affects different traits.

\section{Spear}

The SPEcies At Risk (SPEAR) bioindicator index, based on biological traits, has been shown to be highly sensitive to particular groups of contaminants such as pesticides and relatively independent of confounding factors [18]. The index measures the proportion of sensitive (SPEAR) and less sensitive (SPEnotAR, "SPEcies not At Risk") species and is expressed as a percentage.

The SPEAR concept is applicable for the assessment of the effects of pesticides on invertebrate communities in rivers but not lakes, coastal areas or temporary streams. Sampling must be performed in early summer (around June and July), not too long after peak pesticide application. Sensitivity data and information on other relevant traits for the taxa are included within the database used for the SPEAR online calculator. So far, validation studies have been performed in Finland, Germany, Sweden, France, Spain, Czech Republic and Australia. Nonetheless, there is a need for further validation before the SPEAR index can be used on a routine basis and as part of the WFD classification. In particular, the baseline sensitivity and variability of the method need to be assessed.

\section{Pict}

Pollution-induced community tolerance (PICT) has been suggested as a sensitive tool to track changes in community function (and therefore indicative of structural changes) that can be attributed to toxic substances. The PICT approach was developed by Blanck and Wängberg [19]. The approach relies on the assumption that sensitive components of the exposed community (species, genotypes or phenotypes) will be replaced by more tolerant ones during exposure, thus leading to an increase of community tolerance. PICT is measured by a functional test that detects the consequences of selection pressures. Tolerance development, for example, can be measured as a shift in the effect concentration (usually $\mathrm{EC}_{50}$ ) that is obtained with a short-term toxicity test based on an ecophysiological endpoint. Such an endpoint is preferably related to community metabolism (photosynthesis, respiration, protein synthesis, nucleic acid synthesis etc.). In recent years, PICT combined with the transplantation of periphyton communities has been suggested as a promising tool to identify impaired sites by detecting an induced tolerance after transplantation. In situ PICT assays using transplanted communities have been suggested as a promising tool that can link ecological and chemical status in the WFD context [20]. The PICT approach has the disadvantage that cannot be used to assess the risks for long-lived organisms with complex life cycles (e.g. insects and vertebrates).

\section{EDA and TIE}

While effect-based monitoring indicates hazards due to chemical contamination and provides information on toxicological endpoints of concern, tools are required to identify causes and elucidate links between exposure and effects. EDA and TIE are integrated biological and chemical approaches which aim to identify those compounds in an environmental or technical sample (water, soil, sediment, air, food, consumer product and technical mixture) that cause a biological response. Both approaches combine biotesting, physicochemical fractionation and chemical analysis in a sequential procedure. However, the philosophy behind both approaches is slightly different [21]. The TIE approach has its origin in whole effluent testing, which focuses on the question, whether an effluent will cause adverse effects on aquatic organisms when emitted to the environment. In the case that effects are detected in whole organisms under realistic exposure conditions, TIE should help to characterise and identify the cause of the measured effect. Thus, TIE applies in vivo biotesting and avoids extraction and preconcentration steps as far as possible.

EDA is based on the understanding that environmental samples may contain thousands of mostly organic chemicals and that only a fraction of them can be analysed by chemical target analysis. EDA takes a biological effect (typically observed by effect-based monitoring) as the basis to narrow down the huge amount of possible chemical substances and aims to direct chemical analysis to those compounds that contribute significantly to a measurable effect. Thus, in EDA, bioassays are considered as tools to sensitively detect chemicals with similar biological targets or modes of action. The focus of EDA is on unravelling the contamination with organic toxicants representing the most complex group of chemicals. Similar to chemical analysis, there are no restrictions with respect to extraction or pre-concentration. Since the isolation 
and identification of individual toxicants out of thousands of components in typical environmental mixtures often demand for large numbers of fractions, high-throughput tools are preferred. In addition, the identification of unknown toxicants is very much supported by information on the mode of action. Both criteria are often met best with in vitro assays, although small-scale in vivo assays may be helpful, too [22]. The sample or an extract thereof is tested with the bioassays of choice depending on the objective of the study. If effects are detectable, the mixture is fractionated according to the physico-chemical properties of the components. The fractions are tested with the same bioassays for prioritisation according to effects. The mixture may undergo several fractionation steps to further reduce complexity. The components of active fractions are identified and quantified by chemical analytical means. Depending on the objective of the study, in a final confirmation step, the contribution of the identified candidate compound to the measured effect should be quantified or estimated in order to exclude that major contributors have been overlooked.

The major components of EDA are (i) separation including extraction, clean up and fractionation, (ii) biotesting, (iii) chemical analysis including computational tools for structure elucidation and (iv) confirmation.

EDA is a tool for investigative monitoring at selected sites of particular interest or with conspicuous effects. EDA aids in linking ecological status to contamination, to establish cause-effect relationships and to target mitigation measures. Although providing enormous progress over present target chemical monitoring, a general limitation of EDA is the requirement to pre-select toxicological endpoints. The combination of integrating whole organism tests with in vitro test batteries applying sufficient pre-concentration reduces the risk to overlook important effects and thus toxicants.

\section{OMICS}

The recent advances in DNA sequencing and characterisation of genomes have opened up a range of new possibilities. A particular field of molecular studies within biology is called "Omics" and refers to high-throughput molecular profiling technologies, such as genomics, metagenomics, transcriptomics, proteomics, metabolomics and metabonomics. The suffix "-ome" refers to the collection of all genes or gene products such as the genome, proteome or metabolome, respectively. A study of all or a very large number of these genes would fall under the definition of omics. Omics and bioinformatics tools can e.g. be used to:

- Develop molecular biomarkers of exposure as early signals to predict effects (that at a later stage could have an impact on physiological level and further on at population level).
- Provide information about the mode of action (MOA) of chemicals, i.e. the mechanism of toxicity; in turn, reducing the uncertainties involved in chemical risk assessment by providing, for example, a basis for extrapolation of the effects across species.

- Integrate MOA data with a deleterious outcome and in this way, aid towards understanding the impact on the ecosystem instead of just on single organism or species.

- Distinguish the site of origin of organisms, based on the transcriptomics changes in organisms coming from different locations.

\section{Genomics-DNA microarray applications}

Genomics can be indicative of the susceptibility of an organism for a certain chemical or group of chemicals [23] and are more frequently also been used for assessment of complex environmental samples, such as sediments [24]. A DNA microarray is a glass slide or a nylon membrane on which part of the organism's gene sequences (probes) is spotted or synthesised. Normally, complementary DNA (cDNA) is made using reverse transcriptase from RNA in the sample to be analysed. Then, the cDNA is thereafter hybridised to the array. After scanning and image analysis, the RNA abundance (amount of RNA molecules bound to the complementary probes on the microarray) is analysed and the relative gene expression of the treated sample can be compared to the untreated control.

\section{Next-generation sequencing}

The development of DNA sequencing technology four decades ago was a major scientific hallmark and opened the doors for several breakthrough achievements in all areas of biology. Next-generation sequencing (NGS) is a more recent technology, also named second-generation sequencing (SGS) and has been commercially available since 2004.

Compared to the first-generation capillary electrophoresis (CE)-based Sanger sequencing, NGS has increased sequencing speed, the throughput to millions of sequencing experiments on fragmented DNA run in parallel, has reduced sequencing costs per base pair in some cases more than 10,000 fold. NGS platforms enable a wide variety of applications including the study of the genome or transcriptome of any organism.

\section{RNA-seq}

RNA-seq is a recently developed approach, extending the high-throughput sequencing to the profiling of the transcriptome. Instead of capturing transcript molecules by molecular hybridisation, as on microarrays, RNA-seq directly sequences the transcripts present in a sample. Transcript sequences are then mapped back to a reference genome and counted to assess the expression level of that gene or genomic region [25]. 


\section{Metagenomics}

In recent years, a tremendous increase in DNA sequencing capacity, combined with an unprecedented drop in price per obtained nucleotide sequence, has made it possible to study the functional elements of a microbial ecosystem at the levels of the actual genes responsible for these functions. Such sequencing studies of the total DNA content of an environment are generally referred to as metagenomics [26] and could be used to pinpoint the genes or species that cause, for example, a PICT response. A possible relevant use of metagenomics is to monitor the presence and abundance of antibiotic resistance genes in the environment.

\section{Proteomics}

Proteomics is the large-scale study of proteins, particularly their structures and functions [27]. After genomics and transcriptomics, high-throughput proteomics is considered the next step in the study of biological systems. It is much more complicated than genomics mostly because while an organism's genome is more or less constant, the proteome differs from cell to cell and from time to time. This is because distinct genes are expressed in distinct cell types. This means that even the basic set of proteins which are produced in a cell needs to be determined.

\section{Metabolomics}

Within metabolomics, the endogenic metabolic profile of an organism is studied. The metabolites that are studied can be considered to be the result of the ongoing metabolic activity of the cells. To measure metabolites is considered advantageous since it is well known that metabolites are formed at an early stage of environmental stress [28].

\section{Conclusions}

The topic "effect-based tools" highly ranked in the CIS science-policy interface report [29] elaborated on the basis of inputs from the Working Group "Chemicals" of the WFD”. The new mandate 2013 to 2015 of the Working Group, approved by the Water Directors, has foreseen the continuation of the activity on effect-based tools, in particular, in relation to the detection and evaluation of effects caused by mixtures of pollutants. This activity will be strongly linked to the work of the WG Ecostat and the implementation needs of the MSFD. Furthermore, a project has been planned with the aim to evaluate the use of bioanalytical methods for the detection of the pharmaceuticals $17 \alpha$-ethinylestradiol (EE2) and 17ßestradiol (E2) which are included in the WFD "Watch List" of emerging pollutants foreseen by the Directive 2013/39/EU. This technical report, elaborated in close collaboration with the scientific community, can already be considered to provide important support to the managers, assessors and local operators involved in the analysis and monitoring of surface water bodies.

\section{Appendix}

The Appendix section of the technical report on aquatic effect-based monitoring tools (Additional file 2) collects 14 case studies (Table 4), which illustrate how these tools can help to achieve the objectives of the WFD and MSFD and a series of fact-sheets (Table 5) that provide technical specifications for selected individual effectbased tools (biomarkers and bioassays) that are either already used on a routine basis or are gaining in popularity.

The Appendix section contains also a list of available standardized effect-based tools (in vivo and in vitro, bioassays and biomarkers), established assessment criteria for the marine environment and an overview of available DNA microarrays. Other technical issues, such as sampling aspects, standardization and proposed approaches to assess estrogenic effects are also described in more detail in the Appendix section. Finally, a list of definitions, abbreviations and a wide bibliography section on the topic is included.

\section{Table 4 Case studies}

\section{Case studies}

1 Laxsjön - investigating sediment contamination using chemical and in vitro bioassay approach

2 Deployment of a multi-biomarker approach to identify the origin of wild fish abnormalities reported in a French stream receiving urban and industrial effluents.

3 Endocrine disruptors in the Irish aquatic environment

$4 \quad$ Swedish national monitoring programme of fish health

5 Evaluation of aquatic environmental estrogens with passive sampling - EPSA

6 Contaminated sediments in the River Elbe basin-EDA

$7 \quad$ Monitoring concentrated surface water with in vivo bioassays in the Netherlands

$8 \quad$ Monitoring imposex on water body level

9 Bioassays for monitoring the offshore platform impacts and their main discharges

10 Evaluation of the utility of microarrays as a biomonitoring tool in field study

11 Use of DNA microarray to test the water quality of river East Turkey Creek (bay of watershed of Florida) potentially impacted by treated wastewater from sprayfield area

12 The risk of chronic impact of pollution on the Bílina River

13 Mechanism-specific tools with zebrafish early life stages in EDA of surface waters

14 Multicriteria assessment of human activity effects on water ecosystems: the case study of Tiber River basin 
Table 5 Fact-sheets for certain biomarkers and bioassays

\begin{tabular}{|c|c|}
\hline & Fact-sheets of biomarkers and bioassays \\
\hline \multirow[t]{22}{*}{ Biomarker } & Metallothionein (MT) \\
\hline & ALA-D \\
\hline & Cytochrome P450 1A activity (EROD; CYP 1A activity) \\
\hline & DNA adducts \\
\hline & PAH metabolites \\
\hline & Liver histopathology (LH) \\
\hline & Macroscopic liver neoplasm (MLN) \\
\hline & Externally visible fish diseases \\
\hline & Reproductive success in eelpout \\
\hline & Vitellogenin \\
\hline & Intersex (in male fish) \\
\hline & Lysosomal stability \\
\hline & Imposex biomarkers \\
\hline & Micronucleus assay \\
\hline & Amphipod embryo alterations \\
\hline & Stress proteins (heat shock protein) \\
\hline & Acetylcholinesterase (AChE) assay \\
\hline & Comet Assay \\
\hline & Mussel histopathology (gametogenesis) \\
\hline & Stress on stress \\
\hline & Scope for Growth (SFG) \\
\hline & Benthic diatom malformation \\
\hline \multirow[t]{9}{*}{ Bioassay } & DR CALUX/DR Luc assay \\
\hline & PAH CALUX \\
\hline & ERa CALUX/ER-Luc (agonistic/antagonistic) \\
\hline & AR CALUX (agonistic/antagonistic) \\
\hline & YES \\
\hline & YAS \\
\hline & Ames fluctuation test \\
\hline & Micronucleus assay \\
\hline & Fish embryo acute toxicity (FET) test \\
\hline
\end{tabular}

\section{Additional files}

Additional file 1: Technical report [6] on aquatic effect-based monitoring tools under the Water Framework Directive [1]. The entire report is available as supplementary material to this article and from the website of the European Commission. https://circabc.europa.eu/ sd/a/0d78bbf7-76f0-43c1-8af2-6230436d759d/Effect-based\%20tools\% 20CMEP\%20report\%20main\%2028\%20April\%202014.pdf.

Additional file 2: Technical report on aquatic effect-based monitoring tools (Appendix). The entire report is available as supplementary material to this article.

Competing interests

The authors declare that they have no competing interests.

\section{Authors' contributions}

All authors are responsible for the general design of the Technical Report. ASW and MC wrote the first draft of the manuscript. All authors contributed on specific aspects, read and approved the final manuscript.

\section{Acknowledgements}

We acknowledge the Members of WG "Chemicals" (previous "Chemical Aspects") of the WFD for the contribution and the useful comments provided for the revision of the technical report.

\section{Author details}

'Swedish Agency for Marine and Water Management, Gullbergs Strandgata 15, Göteborg 404 39, Sweden. ${ }^{2}$ Department of Environment and Primary Prevention, ISS-Italian Institute of Health, Viale Regina Elena, 299, 00161 Rome, Italy. ${ }^{3}$ ISPRA - Institute for Environmental Protection and Research, Via Brancati 48, 00144 Rome, Italy. ${ }^{4}$ T.G. Masaryk Water Research Institute, Podbabská 2582/30, 6, 16000 Praha, Czech Republic. ${ }^{5}$ National Institute for Industrial Environment and Risks INERIS, Rue Jacques Taffanel, 60550 Verneuil en Halatte, France. 'Baltic Eye, Östersjöcentrum, Stockholms Universitet, SE-106 91, Universitetsvägen 10 A, Stockholms, Sweden. ${ }^{7}$ Federal Institute of Hydrology, Am Mainzer Tor 1, 56068 Koblenz, Germany. ${ }^{8}$ Rijkswaterstaat, Water, Traffic and Environment, Zuiderwagenplein 2, 8224 Lelystad, The Netherlands. ${ }^{9}$ National Institute for Public Health and the Environment (RIVM), 3720, Postbus 1BA, Bilthoven, The Netherlands. ${ }^{10}$ EPA, Johnstown Castle Estate, PO Box 3000, Wexford, Ireland. ${ }^{11}$ IRSA-CNR, Via del Mulino 19, 20047 Brugherio, Italy. ${ }^{12}$ Swedish Environmental Protection Agency, Naturvårdsverket, SE-106 48 Stockholm, Sweden. ${ }^{13}$ University of Gothenburg, Guldhedsgatan 10, SE-405 30 Gothenburg, Sweden. ${ }^{14}$ Swiss Centre for Applied Ecotoxicology Eawag-EPFL, Überlandstrasse 133, CH-8600 Dübendorf, Switzerland. ${ }^{15}$ Marine Scotland Science, 375 Victoria Road, AB11 9DB Aberdeen, Scotland. ${ }^{16}$ Cefas, Pakefield Road, Lowestoft, Suffolk NR33 OHT, UK. ${ }^{17}$ Defra, Area 3D, Nobel House, Smith Square, London SW1P 3JR, UK. ${ }^{18}$ CONCAWE, Vorstlaan 165, B-1160 Brussels, Belgium. ${ }^{19}$ Eurometaux, Avenue de Broqueville 12, B-1150 Brussels, Belgium. ${ }^{20}$ DG Environment - European Commission, Avenue de Beaulieu 9, B-1160 Brussels, Belgium. ${ }^{21}$ DG Joint Research Centre - European Commission, Via Enrico Fermi 2749, I-21027 Ispra, Italy. ${ }^{22}$ Department of Ecosystem Analysis, Institute for Environmental Research, ABBt RWTH Aachen University, Worringerweg 1, 52074 Aachen, Germany. ${ }^{23}$ Helmholtz Centre for Environmental Research-UFZ, Permoserstraße 15, 04318 Leipzig, Germany. ${ }^{24}$ Thünen-Institut of Fisheries-Ecology, Palmaille 9, 22767 Hamburg, Germany.

Received: 8 December 2014 Accepted: 16 January 2015 Published online: 11 March 2015

\section{References}

1. European Union. Directive 2000/60/EC of the European Parliament and of the Council of 23 October 2000 establishing a framework for Community action in the field of water policy. Off J Eur Union. 2000;L327:1-73.

2. European Union. 2013. Off J Eur Union. 2013;L 226:1-17.

3. European Union: communication from the commission to the council. The combination effects of chemicals. COM/2012/0252 final, 31/05/2012, pp. 1-10.

4. Silva E, Rajapakse N, Kortenkamp A. Something from "nothing" - eight weak estrogenic chemicals combined at concentrations below NOECs produce significant mixture effects. Environ Sci Technol. 2002:2002(36):1751-6.

5. Quevauviller P, Carere M, Polesello S. Chemical monitoring activity for the implementation of the Water Framework Directive. Trends Anal Chem. 2012;36:1-184

6. Wernersson AS, Maggi C, Carere M. Technical report on aquatic effect-based monitoring tools. Technical Report 2014-077. Luxembourg: Office for Official Publications of the European Communities; 2014.

7. Hallare AV, Seiler TB, Hollert $H$. The versatile, changing, and advancing roles of fish in sediment toxicity assessment-a review. J Soils Sedim. 2011;11:141-73.

8. Green N, Schøyen M, Øxnevad S, Ruus A, Høgåsen T, Beylich B, Håvardstun J, Rogne $\AA$, Tveiten L. Hazardous substances in fjords and coastal waters - 2010 Levels, trends and effects. Long-term monitoring of environmental quality in Norwegian coastal waters. Norwegian State Pollution Monitoring Programme Report no. 1111/2011. TA-no. 2862/2011. 252, 2011 
9. Chapman D, Jackson J (1996): Biological monitoring. In Water Quality Monitoring - A Practical Guide to the Design and Implementation of Freshwater Quality Studies and Monitoring Programmes. Edited by Jamie Bartram and Richard Balance Published on behalf of United Nations Environment Programme and the World Health Organization. ISBN 041922320 7. (Hbk) 0419217304 (PBK).

10. Connon RE, Geist J, Werner I. Effect-based tools for monitoring and predicting the ecotoxicological effects of chemicals in the aquatic environments. Sensors. 2012;12:12741-71.

11. Leusch FL, De Jager C, Levi Y, Lim R, Puijker L, Sacher F, et al. Comparison of five in vitro bioassays to measure estrogenic activity in environmental waters. Environ Sci Technol. 2010;44:3853-60

12. Wernersson AS: Swedish monitoring of hazardous substances in the aquatic environment-current vs required monitoring and potential developments. Länsstyrelsen I Västra Götalands län. Rapport 2012:23.

13. Piva F, Ciaprini F, Onorati F, Benedetti M, Fattorini D, Ausili A, et al. Assessing sediment hazard through a weight of evidence approach with bioindicator organisms: a practical model to elaborate data from sediment chemistry, bioavailability, biomarkers and ecotoxicological bioassays. Chemosphere. 2011;2011(83):475-85.

14. Ahlf W, Heise $S$. Sediment toxicity assessment: rationale for effect classes. J Soils Sedim. 2005;5:16-20.

15. Sanchez W, Porcher JM. Fish biomarkers for environmental monitoring within the water framework directive. Trends Anal Chem. 2009;28:150-8.

16. Usseglio-Polatera P, Bournaud M, Richoux P, Tachet H. Biological and ecological traits of benthic freshwater macroinvertebrates: relationships and definition of groups with similar traits. Freshwater Biol. 2000;43:175-205.

17. Van den Brink PJ, Alexander AC, Desrosiers M, Goedkoop W, Goethals PLM, Liess M, et al. Traits-based approaches in bioassessment and ecological risk assessment: strengths, weaknesses, opportunities and threats. Integr Environ Assess Managem. 2011;7:198-208.

18. Schäfer R, Vd Ohe P, Rasmussen J, Kefford B, Beketov M, Schulz R, et al. Thresholds for the effects of pesticides on invertebrate communities and leaf breakdown in stream ecosystems. Environ Sci Technol. 2012;46:5134-42.

19. Blanck H, Wängberg S-Å. Induced community tolerance in marine periphyton established under arsenate stress. Can J Fish Aquat Sci. 1988;45:1816-9.

20. Pesce S, Lissalde S, Lavieille D, Margoum C, Mazzella N, Roubeix V, et al. Evaluation of single and joint toxic effects of diuron and its main metabolites on natural phototrophic biofilms using a pollution-induced community tolerance (PICT) approach. Aquat Toxicol. 2010;99:492-9.

21. Burgess RM, Ho KT, Brack W, Lamoree M. Effect-directed analysis (EDA) and toxicity identification evaluation (TIE) (2013): complementary but different approaches for diagnosing causes of environmental toxicity. Environ Toxicol Chem. 2013;32:1935-45.

22. Brack W. Effect-directed analysis: a promising tool for the identification of organic toxicants in complex mixtures (2003). Anal Bioanal Chem. 2003;377:397-407.

23. Gunnarsson L, Kristiansson E, Larsson DGJ (2012): Environmental comparative pharmacology: theory and application. In B.W. Brooks and D.B. Huggett (eds.), Human Pharmaceuticals in the Environment:Current and Future Perspectives, Emerging Topics in Ecotoxicology 4, doi:10.1007/978-1-4614-3473-3_5, Springer Science + Business Media.

24. Kosmehl T, Otte JC, Yang L, Legradi J, Bluhm K, Zinsmeister C, et al. A combined DNA-microarray and mechanism-specific toxicity approach with zebrafish embryos to investigate the pollution of river sediments. Reprod Toxicol. 2012;33:245-53.

25. Wang Z, Gerstein M, Snyder M. RNA-Seq: a revolutionary tool for transcriptomics. Nat Rev Genet. 2009;10:57-63.

26. Riesenfeld CS, Schloss PD, Handelsman J. Metagenomics: genomic analysis of microbial communities. Annu Rev Genet. 2004;38:525-52

27. Anderson NL, Anderson NG. Proteome and proteomics: new technologies, new concepts, and new words. Electrophoresis. 1998;19:1853-61.

28. Samuelsson LM, Förlin L, Karlsson G, Adolfsson-Erici M, Larsson JDG. Using NMR metabolomics to identify responses of an environmental estrogen in blood plasma of fish. Aquat Toxicol. 2006;78(4):341-9.

29. Kase R, Clayton H, Martini F: Science-Policy Interface (SPI) activity on prioritisation of research needs, knowledge availability and dissemination for the Working Group E (Chemical Aspects) 2010-2012. Open available at CIRCABC at: https://circabc.europa.eu/w/browse/5bf63ff3-b24b-4365-8a5738e4d56b941.

\section{Submit your manuscript to a SpringerOpen ${ }^{\circ}$ journal and benefit from:}

- Convenient online submission

- Rigorous peer review

- Immediate publication on acceptance

- Open access: articles freely available online

- High visibility within the field

- Retaining the copyright to your article

Submit your next manuscript at $>$ springeropen.com 